\title{
Performance of asphalt mixes with high recycling rates for wearing layers
}

\author{
Anita BlasI ${ }^{1,}$, , Juliane Kraft ${ }^{1}$, Davide Lo Presti ${ }^{2}$, Gaetano Di Mino ${ }^{3}$, Frohmut Wellner ${ }^{1}$ \\ ${ }^{1}$ Institute for Pavement and Urban Engineering, Technical University of Dresden, Dresden, Germany \\ 2 Faculty of Engineering, University of Nottingham, Nottingham, United Kingdom \\ ${ }^{3}$ Department of Civil, Environmental, Aerospace, Materials Engineering, University of Palermo, Palermo, Italy \\ a anita.blasl@tu-dresden.de \\ Digital Object Identifier (DOI): dx.doi.org/10.14311/EE.2016.296
}

\begin{abstract}
The corresponding paper presents selected results of a research on the feasibility of going toward 100\% recycling of asphalt pavements into surface courses through an increasing percentage of RA within the mixes. The research is carried out within a two-year CEDR Transnational Road Research project, AllBack2Pave, led by the Technische Universitaet Dresden (Germany), together with the University of Nottingham (UK) and the University of Palermo (Italy), and finalised in January 2016.

The main objectives of the project are - to establish, through laboratory tests on binders and asphalt mixes, whether the use of high rates of RA is feasible in developing mixes with high level of durability, and - to develop a "AllBack2Pave end-user manual" on how to best produce cost-effective and high-quality asphalt mixes with high RA content followed by a sustainability assessment of the practice of using asphalt surface mixes with high recycling rates based on chosen European case studies to identify the most cost-effective solutions, together with their environmental impact over the whole lifecycle of selected road pavements.

The paper focus on selected results of laboratory tests conducted for different types of representative asphalt surface mixes with different amounts of reclaimed asphalt as well as for the bitumen extracted from the investigated asphalt mixes.

In detail, the thermal cracking resistance of the used bitumen will be analysed and critical temperatures will be given. Regarding the asphalt mixes, the stiffness behaviour and the rutting resistance of all materials will be discussed.
\end{abstract}

Keywords: Additives, Asphalt, Performance testing, Reclaimed asphalt pavement (RAP) Recycling, Rejuvenators 


\section{INTRODUCTION}

Given today's societal concerns with environmental protection and sustainable development in a post-fossil fuel era, road authorities in Europe are working together to make the dismantling and end-of-life strategies of asphalt pavements more energy efficient. In this context, the amount of recycling of reclaimed asphalt (RA) in new asphalt pavements has grown to the point that it is no longer a simple green construction alternative but a common practice in almost all of Europe. In recent years, due to the rising cost of asphalt binder, new efforts have been made to increase the amount of RA used in asphalt pavements. Several interdisciplinary research projects related to the usage of hot mix asphalts with RA have been carried-out in Europe during the last decades (Direct-MAT 2011 [1], Re-Road 2012 [2]). The outcome of these projects showed that the durability of mixes with RA proved to be satisfactory. However, in general, the share of recycling of RA in new asphalt courses remains rather lower than it could be technically. Highway authorities together with the asphalt paving industry worked together to develop new methods and design approaches to increase the share of recycling in pavement construction and rehabilitation. Economic and environmental benefits are the driving forces behind research in asphalt pavement recycling. Economic benefits are mainly associated with the reduction of use of virgin materials (aggregates and binder). The environmental profit include reduced emission and energy consumption in the production and transportation of virgin materials as well as reduced demand of non-removable resources.

Despite of the above mentioned benefits, the amount of RA used in wearing courses in Europe is very limited. There is a common concern that the high quality material requirements for wearing courses are not met if the major volumetric component of the mix originates from a recycled material. The background of this objection is the inherit heterogeneity of the RA, which properties depend in great extent on factors such as the technique used to reclaim the asphalt, the maintenance history of the road, the storage conditions, etc., which are not considered in standard mix design procedures. The production of asphalt mixtures for road pavements is now an entirely automatic process that implies an adequate mix design procedure carried out in laboratory. Whatever technique is used, the mix design process is the crucial moment in order to produce the asphalt mixture having the required performance characteristics within the road pavement. Generally these performances can be identified as: workability and susceptibility to compaction during the mixing and the laying; fatigue resistance and resistance to rutting during the service in life. Possibly the mix design process is even more crucial when we have to design asphalt mixes with relevant percentage of the Reclaimed Asphalt (RA) because of the variability of such materials.

This paper summarises selected results of research on the feasibility of going toward $100 \%$ recycling of asphalt pavements into wearing courses through an increasing percentage of RA within the mixes. The research is carried out within a twoyear CEDR Transnational Road Research project, AllBack2Pave, led by the Technische Universitaet Dresden (Germany), together with the University of Nottingham (UK) and the University of Palermo (Italy), and has been finalised in autumn 2015 .

In several countries, a successful realisation of wearing course layers with different recycling rates has already been reported [1-4], however, mostly without giving detailed reproducible information about mix design procedures followed by comprehensive laboratory analysis of the used materials.

The main objectives of the Allback2Pave project are - to establish, through laboratory tests on binders and asphalt mixes, whether the use of high rates of RA (from $0 \%$, control mix, to the closest feasible amount to $100 \%$ RA) is feasible in mixes with high level of durability, and - to develop an "AllBack2Pave end-user manual" on how to best produce costeffective and high-quality asphalt mixes with high RA content. This is complemented by design life calculations using one in Germany established mechanistic empirical design method as well as by a sustainability assessment of the practice of using asphalt surface mixes with high recycling rates based on chosen European case studies to identify the most costeffective solutions, together with their environmental impact over the whole lifecycle of selected road pavements.

\section{MATERIALS TESTED}

The mixes selected for the investigations are typical asphalt mixes for wearing courses of road pavements of high volume roads used in Germany and in Italy. The mix design of the German asphalt mixtures has been carried out for a stone mastic asphalt (SMA) with a nominal grain size of $8 \mathrm{~mm}$ (SMA 8S), and a polymer-modified bitumen (PmB 25/55-55). The mix design of the Italian asphalt mixtures has been carried out for an asphalt concrete (AC) with a nominal grain size of $16 \mathrm{~mm}$ and paving bitumen.

In order to identify the effect of the RA in the performance of the mix, three variants of the SMA 8S were designed with an increasing percentage of RA: one control mix without RA, one mix with high percentage of RA (30\%) and one experimental mix with very high percentage of RA (60\%). In addition, the effect of using a rejuvenator pre-blended with a warm mix additive was also investigated. Therefore additives have been added to a fourth mixture similar to the SMA mixture with $60 \%$ RA. The RA used for the production of the German asphalt mixes, has also been a SMA with polymer modified bitumen. 
The German asphalt mixes were designed and produced according to the German regulatory environment for hot asphalt mixes with RA.

Similar to the SMA mixes, the AC mixes were also designed with an increasing percentage of RA: one control mix without RA, one mix with high percentage of RA (30\%) and two experimental mixes with very high percentage of RA (60\% and $90 \%$ RA). In this case, the RA used for the production of the Italian asphalt mixes, except the control mix, has also been an AC with paving bitumen. However, the used RA was a relatively old asphalt so that it was necessary to add additives (the same as used for the SMA mixes) to all AC mixes incorporating RA.

Table 1. Material composition of the investigated German and Italian asphalt mixtures mixed in plant

\begin{tabular}{|c|c|c|c|c|}
\hline Description & $\begin{array}{c}\text { SMA 8S with } \\
\text { 0\% RA }\end{array}$ & $\begin{array}{l}\text { SMA 8S with } \\
\text { 30\% RA }\end{array}$ & $\begin{array}{c}\text { SMA 8S with } \\
\text { 60\% RA }\end{array}$ & $\begin{array}{c}\text { SMA 8S with } \\
\text { 60\% RA + } \\
\text { Additive }\end{array}$ \\
\hline Binder content [M.-\%] & 7.29 & 7.19 & 7.02 & 7.64 \\
\hline Ring \& Ball softening point $\left[{ }^{\circ} \mathrm{C}\right]$ & 67.9 & 74.1 & 82.5 & 61.8 \\
\hline Bulk density selected [g/cm³] & 2.331 & 2.357 & 2.344 & 2.354 \\
\hline Description & $\begin{array}{c}\text { AC } 16 \text { with } \\
\text { 0\% RA }\end{array}$ & $\begin{array}{c}\text { AC } 16 \text { with } \\
\text { 30\% RA + } \\
\text { Additives } \\
\end{array}$ & $\begin{array}{c}\text { AC } 16 \text { with } \\
60 \% \text { RA + } \\
\text { Additives } \\
\end{array}$ & $\begin{array}{c}\text { AC } 16 \text { with } \\
90 \% \text { RA + } \\
\text { Additives } \\
\end{array}$ \\
\hline Binder content [M.-\%] & 6.10 & 6.00 & 5.73 & 4.40 \\
\hline Ring \& Ball softening point $\left[{ }^{\circ} \mathrm{C}\right]$ & 52.0 & 60.7 & 77.05 & 65.15 \\
\hline Bulk density selected $\left[\mathrm{g} / \mathrm{cm}^{3}\right]$ & 2.509 & 2.503 & 2.554 & 2.420 \\
\hline
\end{tabular}

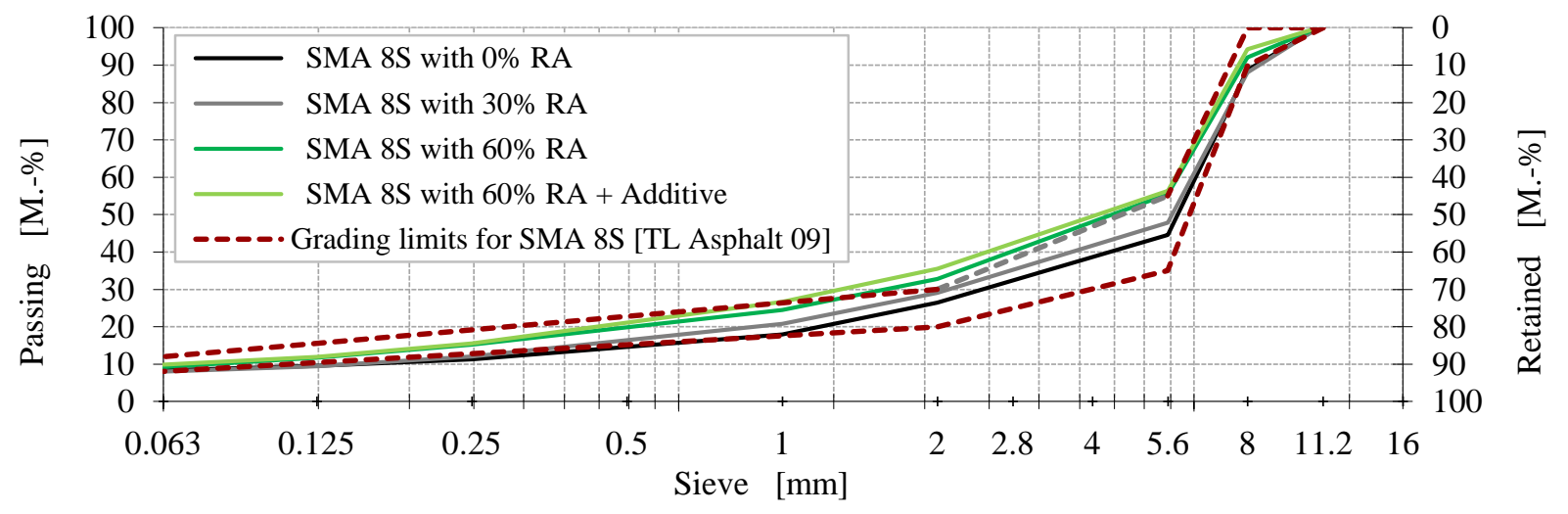

Figure 1. Grading limits for SMA 8S according to the German specification TL Asphalt 09 [6] and gradation of the tested German asphalt mixtures mixed in plant

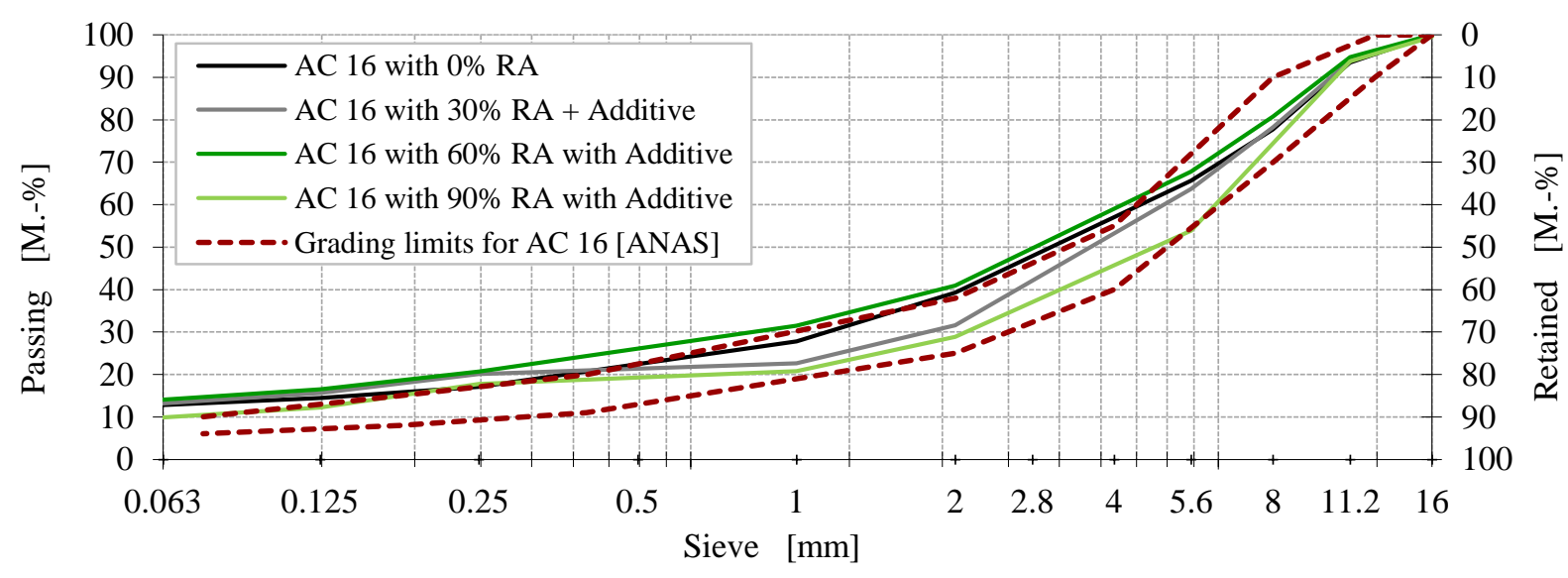

Figure 2. Grading limits for AC 16 according to the Italian specification ANAS [7] and gradation of the tested Italian asphalt mixtures mixed in plant 
The realised different mix design procedures, required by Italian and German specifications, are described in detail in [5]. The German procedure bases on the Marshall-Method. The Italian design method is similar to the Super-Pave-Method.

The final gradations of the investigated asphalt mixtures - mixed in plant - are summarised in Figure 1 and Figure 2. Differences in gradation can be explained by an assumable inhomogeneity of the RA and/or other issues arose during the design procedure. The heterogeneity of RA due to the type of the source (i.e. type of pavement and dismantled layer, utilised milling machine and so on) is against the need of the mix designer who has to reach technical goals on the basis of regulatory framework. Although it cannot be erased every kind of uncertainty, an appropriate characterisation of the RA can reduce the potential of errors to a minimum. Table 1 contains all for this paper relevant information in terms of material composition.

\section{LABORATORY TESTING}

As known, many testing methodologies can be performed to determine the mechanical properties of asphalt mixtures. The tests can be subdivided in two basic categories: the first concerns tests for the implementation of empiricalmechanistic criteria on pavement design; the second regards tests which measure conventional parameters addressed to evaluate some specific properties such as the water sensitivity.

In the light of the fact that the experimental survey on asphalt mixes with high RA rates are not numerous and, above all, the performances of this kind of material depend on several factors in addition to the usual, the test planning should be based on measuring relevant mechanical properties such as stiffness modulus, resistance to fatigue, resistance to permanent deformation and resistance to moisture damage.

On the basis of both the scientific literature and the availability of test devices in the laboratories involved, the mechanical properties of the asphalt mixes were investigated according to the following plan: (i) the stiffness modulus by both Four Point Bending (4PBB) test and Indirect Tensile stiffness Test (ITT); (ii) the resistance to fatigue by 4PBB test and ITT; (iii) the resistance to permanent deformation through both Wheel Tracking Test (WTT) and Uniaxial Compression Test (UCT) and (iv) the resistance to moisture damage by means of Indirect Tensile strength Test. Depending on the test type and national regulations different methods for the production of the required asphalt specimens have been used.

In addition to the performance tests on the eight investigated wearing course asphalt mixes also characterisation of the binders extracted from the final mixes has been carried out in order to assess their rheology, following the plan: Analysis of (i) rutting resistance by Multiple Stress Creep recovery tests; (ii) fatigue resistance by Time Sweep tests and analysis of (iii) the thermal cracking resistance plus the determination of critical temperatures.

This paper focuses on the performance behaviour of the investigated German and Italian asphalt mixes and bituminous binders recovered from the asphalt mixes in terms of stiffness, rutting and low temperature performance in the form of critical temperatures determined for binders.

\subsection{Characterisation of the recovered binders}

The analysed binders were recovered and tested following the procedure described in BS EN 12697-4:2005 [8]. When rejuvenators were present in the mixture, the procedure was modified due to the presence of waxes that exhibited some resistance to be extracted.

\section{Thermal cracking resistance}

In order to characterise thermal cracking resistance of the bitumen at low temperature, flexural creep stiffness $(\mathrm{S}$, in $\mathrm{MPa})$ and m-value are obtained using the Bending Beam Rheometer (BBR). In this test, a beam of bitumen is subjected to bending load in a specific sequence according to BS EN 14771:2012 [9]. The BBR tests are performed at temperatures below zero, in which the temperatures were selected according to previous results in order to obtain the critical ones.

After the test, stiffness (S) is obtained by dividing the bending stress by the bending strain, and m-value is the absolute slope of the curve of the logarithm of the stiffness versus the logarithm of time. The applied test temperatures are summarised in Table 2 and the obtained results are represented in Figure 3 and Figure 4.

Table 2. Testing conditions

\begin{tabular}{|c|c|}
\hline SMA 8 S - Temperature $\left[\mathbf{C}^{\circ}\right]$ & AC 16 - Temperature $\left[\mathbf{C}^{\circ}\right]$ \\
\hline$-18 ;-12$ & $-24 ;-18$ \\
\hline
\end{tabular}


Regarding the stiffness, it was observed that the three SMA bitumen without rejuvenator have very similar values, regardless of the percentage of RA. On the other hand, when the rejuvenator is present, stiffness greatly decreases. This fact means that the binder would show higher resistance to cracking. Regarding Figure 4 it can be seen that the four AC bitumen present different values and that the higher the RA percentage, the lower the stiffness values.

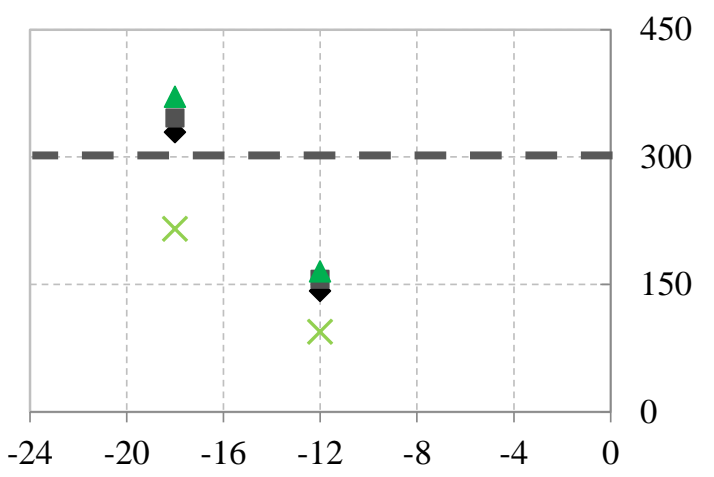

Temperature $\left[{ }^{\circ} \mathrm{C}\right]$

- SMA 8S with 0\% RA

- SMA 8 S with $30 \%$ RA

$\triangle$ SMA 8 S with $60 \%$ RA

$\times$ SMA 8 S with $60 \%$ RA + Additive

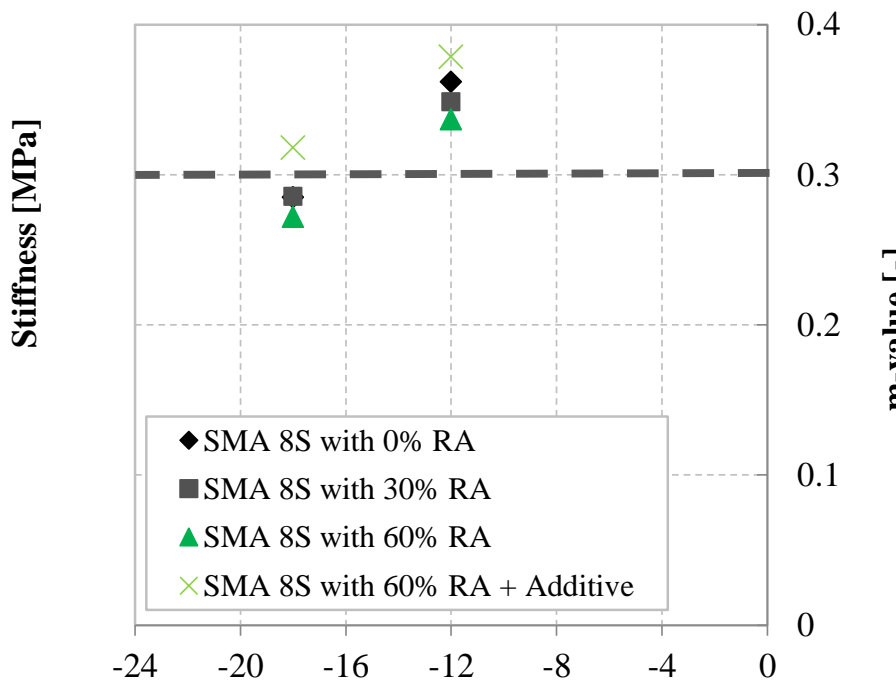

Temperature $\left[{ }^{\circ} \mathrm{C}\right]$

Figure 3. Stiffness and m-value of SMA $8 \mathrm{~S}$ bitumen

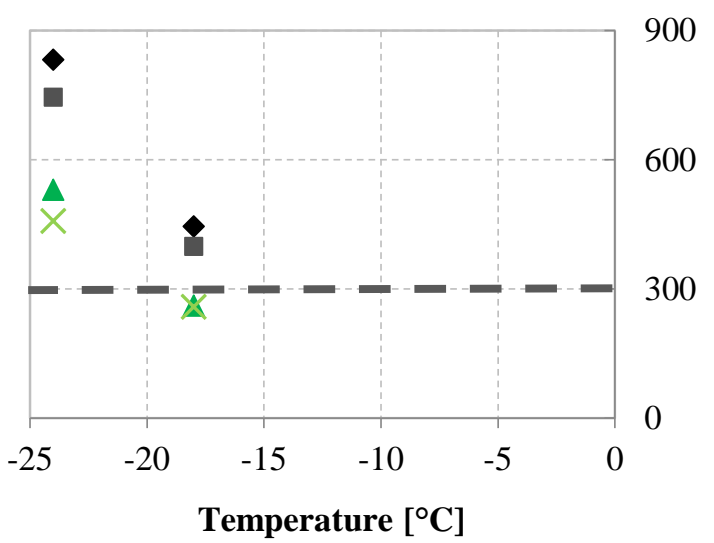

- AC 16 with $0 \%$ RA

aC 16 with $30 \%$ RA + Additive

$\triangle \mathrm{AC} 16$ with $60 \% \mathrm{RA}+$ Additive

$\times$ AC 16 with $90 \% \mathrm{RA}+$ Additive

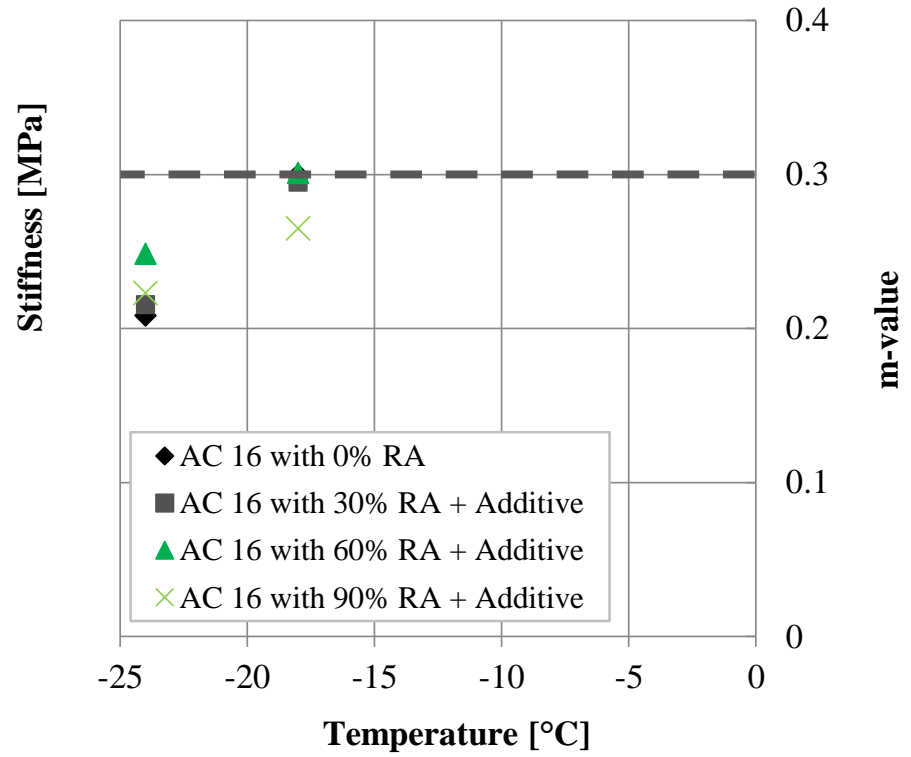

Figure 4. Stiffness and m-value of AC 16 bitumen

Critical temperatures

In order to obtain critical temperatures of the binders and to be able to compare them with the design carried out in the previous stage [5] frequency sweeps in the DSR (BS EN 14770:2012 [10]) were undertaken. The applied test conditions are summarised in Table 3.

Table 3. Testing conditions

\begin{tabular}{|c|c|}
\hline Temperature $\left[\mathbf{C}^{\circ}\right]$ & Frequency $[\mathbf{H z}]$ \\
\hline $0-80$ & 0.1 to 10 \\
\hline
\end{tabular}

In this sense, with the DSR and the BBR results, high, intermediate and low critical temperatures were calculated, summarised in Table 4 and Table 5. 
As is it possible to see the undertaken design provided quite good results for High and Intermediate temperatures, regardless of the amount of RA. With regards to the low critical temperatures, the properties of the recovered binders were worst of the designed ones only when significant amount of additive was used.

Table 4. Critical temperatures of SMA $8 \mathrm{~S}$ binders

\begin{tabular}{|c|c|c|c|c|c|c|c|c|c|}
\hline & \multicolumn{3}{|c|}{$\begin{array}{c}\text { Design critical } \\
\text { temperatures }\left[{ }^{\mathbf{0}} \mathbf{C}\right]\end{array}$} & \multicolumn{2}{c|}{$\begin{array}{c}\text { Recovered binder critical } \\
\text { temperatures }\left[{ }^{\mathbf{C}} \text { ] }\right.\end{array}$} & \multicolumn{3}{c|}{ Relative error [\%] } \\
\hline Mixture & High & Int & Low & High & Int & Low & High & Int & Low \\
\hline SMA 8S & 80.1 & 22.5 & -13.5 & 81.4 & 19 & -16.8 & 1.6 & -15.6 & 24.4 \\
\hline $\begin{array}{c}\text { SMA 8S with } \\
\text { 30\% RA }\end{array}$ & 79.5 & 19.8 & -15.5 & 83.6 & 19.9 & -16.6 & 5.1 & 0.4 & 7.1 \\
\hline $\begin{array}{c}\text { SMA 8S with } \\
\text { 60\% RA }\end{array}$ & 79.7 & 20.5 & -15.0 & 85.6 & 21.8 & -16.4 & 7.4 & 6.4 & 9.4 \\
\hline $\begin{array}{c}\text { SMA 8S with } \\
\text { 60\% RA } \\
\text { + Additive }\end{array}$ & 79.1 & 18.7 & -15.5 & 76.5 & 17.1 & -19.8 & -3.3 & -8.4 & 28.0 \\
\hline
\end{tabular}

Table 5. Critical temperatures of AC 16 binders

\begin{tabular}{|c|c|c|c|c|c|c|c|c|c|}
\hline & \multicolumn{3}{|c|}{$\begin{array}{c}\text { Design critical } \\
\text { temperatures }\left[^{\mathbf{0}} \mathbf{C}\right]\end{array}$} & \multicolumn{3}{c|}{$\begin{array}{c}\text { Recovered binder critical } \\
\left.\text { temperatures } \mathbf{~}^{\mathbf{0}} \mathbf{C}\right]\end{array}$} & \multicolumn{3}{c|}{ Relative error [\%] } \\
\hline Mixture & High & Int & Low & High & Int & Low & High & Int & Low \\
\hline AC16 & 66 & 19 & -16 & 75.4 & 19.8 & -14.2 & 14.2 & 4.2 & -11.3 \\
\hline $\begin{array}{c}\text { AC16 with } \\
30 \% \text { RA } \\
\text { + Additive }\end{array}$ & 67.3 & 16.7 & -16.7 & 76.8 & 19.7 & -15.3 & 14.1 & 18 & -8.4 \\
\hline $\begin{array}{c}\text { AC16 with } \\
\text { 60\% RA } \\
\text { + Additive }\end{array}$ & 68.8 & 14.4 & -18.4 & 78.8 & 18.5 & -18.1 & 14.5 & 28.5 & -1.6 \\
\hline $\begin{array}{c}\text { AC16 with } \\
\text { 90\% RA } \\
\text { + Additive }\end{array}$ & 70.9 & 11 & -21 & 83.9 & 21.6 & -13.0 & 18.3 & 96 & -38.1 \\
\hline
\end{tabular}

As a general trend, the critical temperatures of the SMA binder with $30 \%$ and $60 \%$ RA were very similar to that of the control mix with 0\% RA. For the binder containing the rejuvenator, the low critical temperature was even lower thanks to the effect of the additive. Regarding the binder recovered from the AC mixes. The one with $30 \%$ RA + Additive presented slightly lower temperatures to the $0 \%$ RA binder. This was even lower for the $60 \%$ RA + Additive binder, most likely due to the effect of the additive. Analysing the $90 \%$ case with additives, the temperature is also much higher than the calculated on the design stage. An explanation could be that the AC mixture with $90 \%$ RA + Additives has been produced in laboratory, following under other conditions than the mixtures mixed in plant.

\subsection{Characterisation of the asphalt mixes}

$\underline{\text { Stiffness behaviour }}$

Different repeated load test methods have been established worldwide to investigate the stiffness and fatigue characteristics of asphalt mixes. Within the related research project Four Point Bending Beam Tests according to EN 12697-26 [11] and EN 12697-24 [12] as well as Indirect Tensile tests according to AL Sp-Asphalt 09 [13] have been carried out to analyse the stiffness and fatigue performance of the eight asphalt mixes incorporating different amounts of RA. The outcomes of these tests are most commonly used to determine fatigue parameters (presented as fatigue curves) as well as E-Modulus-temperature-functions and/or Master Curves. For the evaluation of both different methods of analyses have been applied. The developed Master Curves of the eight investigated asphalt mixes, according to Arrhenius approach, are illustrated in Figure 5 and Figure 6. The results of the fatigue related tests are not included in this paper. The applied test conditions are summarised in Table 6. The required specimens have been drilled and cut from asphalt slabs produced by roller sector compaction, what is a typical Germany standard. 
Regarding the SMA mixes (Figure 5) in can be concluded that, as expected, the stiffness increases with an increasing amount of reclaimed asphalt. However, the asphalt mixture with $60 \%$ RA + Additive shows a lower stiffness due to the presence of additives. As already explained above, the fourth SMA mixes has been designed as an experimental asphalt mixture, where originally the allowance of additives was not required by the results of the laboratory tests on recovered binders in line with the mix design procedure. For comparison, the AC mixes (Figure 6) show almost no difference between the temperature related stiffness's apart from the mixture with $90 \%$ RA + Additives. It seems that the added additive has completely compensate the influence of the RA. The reason for the differing stiffness of the fourth AC mixture could be the fact that this mixture had to be produced in laboratory.

Table 6. Testing conditions

\begin{tabular}{|c|c|c|}
\hline Temperature $\left[\mathbf{C}^{\circ}\right]$ & Frequency $[\mathbf{H z}]$ & Test mode $[-]$ \\
\hline-10 to 30 & 0.1 to 20 & Force/position controlled \\
\hline
\end{tabular}

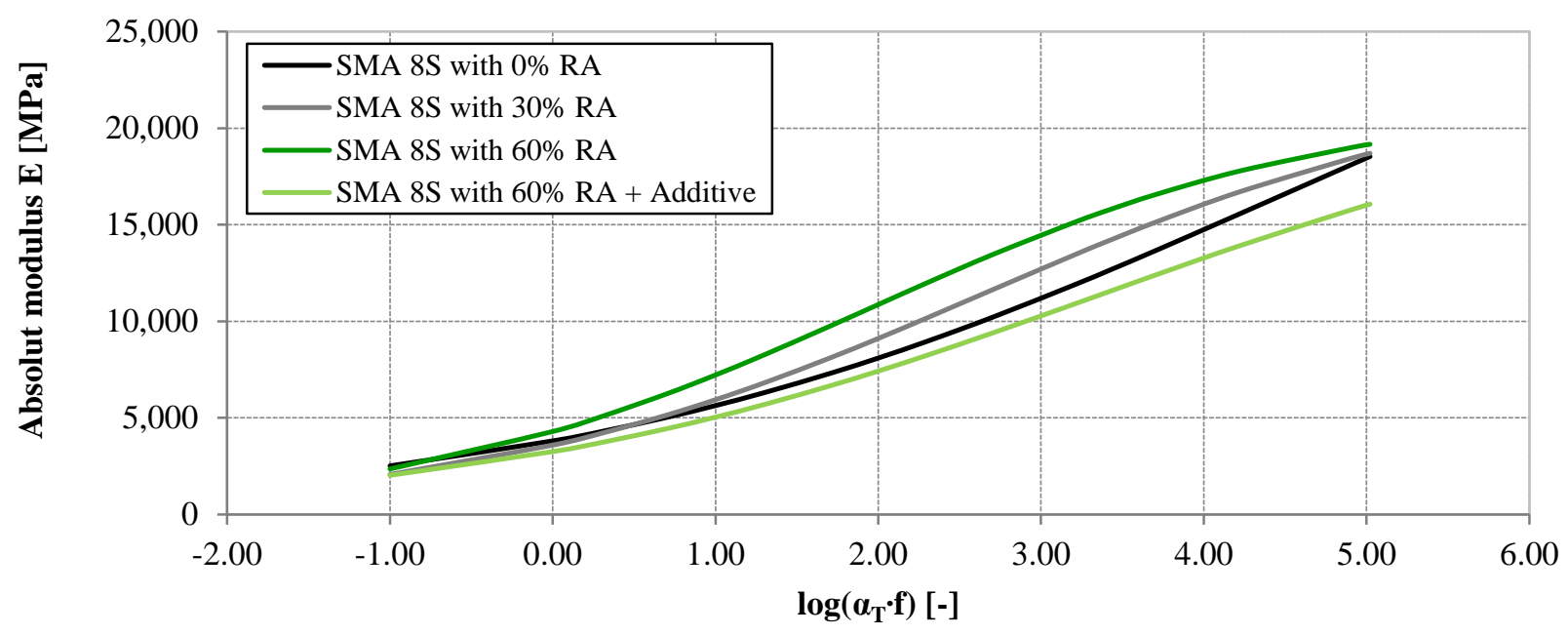

Figure 5. Master curve of SMA $8 \mathrm{~S}$ asphalt mixes @ a reference temperature of $\mathrm{T}_{\mathrm{Re}}=20^{\circ} \mathrm{C}$

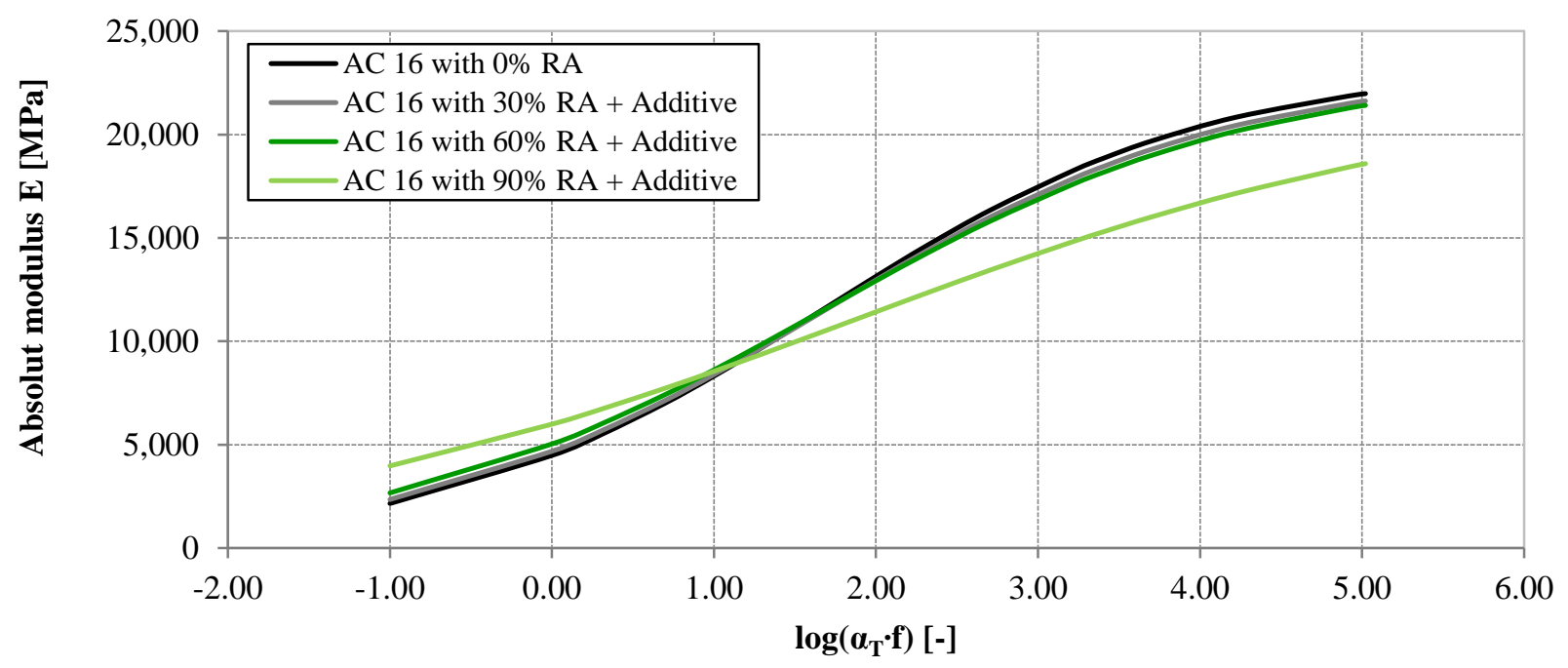

Figure 6. Master curve of AC 16 asphalt mixes @ a reference temperature of $\mathrm{T}_{\text {Ref }}=20^{\circ} \mathrm{C}$

Moisture damage resistance

The moisture damage resistance has been analysed using the indirect tensile strength test according to EN 12697-12 [14] and EN 12697-23 [15]. The required specimens have been produced by gyratory compaction. Figure 7 shows the Indirect Tensile Strength Ratio (ITSR), Figure 8 the Indirect Tensile Strength (ITS). It can be concluded that all mixes show no appreciable sensitivity to moisture damage. However, it can be deduced that the ITS value increases with an increasing RA quantity. Additionally, it seems that the ITS value decreases with the presence of rejuvenating additives. 


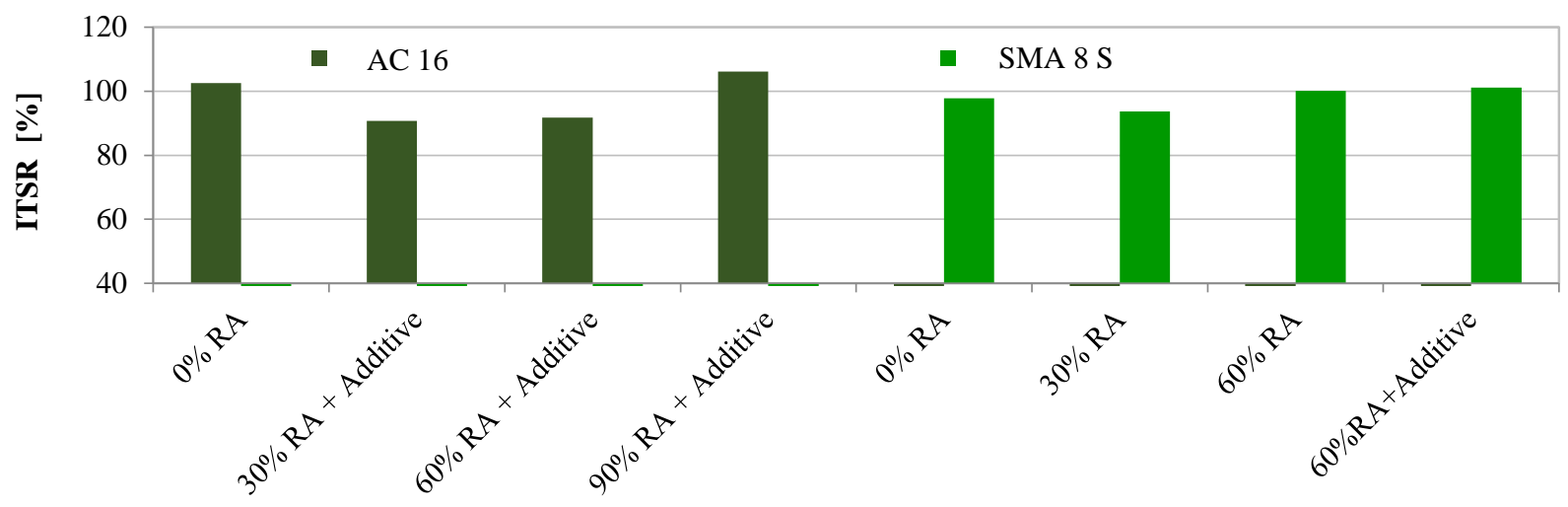

Figure 7. Indirect Tensile Strength ratio (ITSR) for the SMA $8 \mathrm{~S}$ and AC 16 asphalt mixes
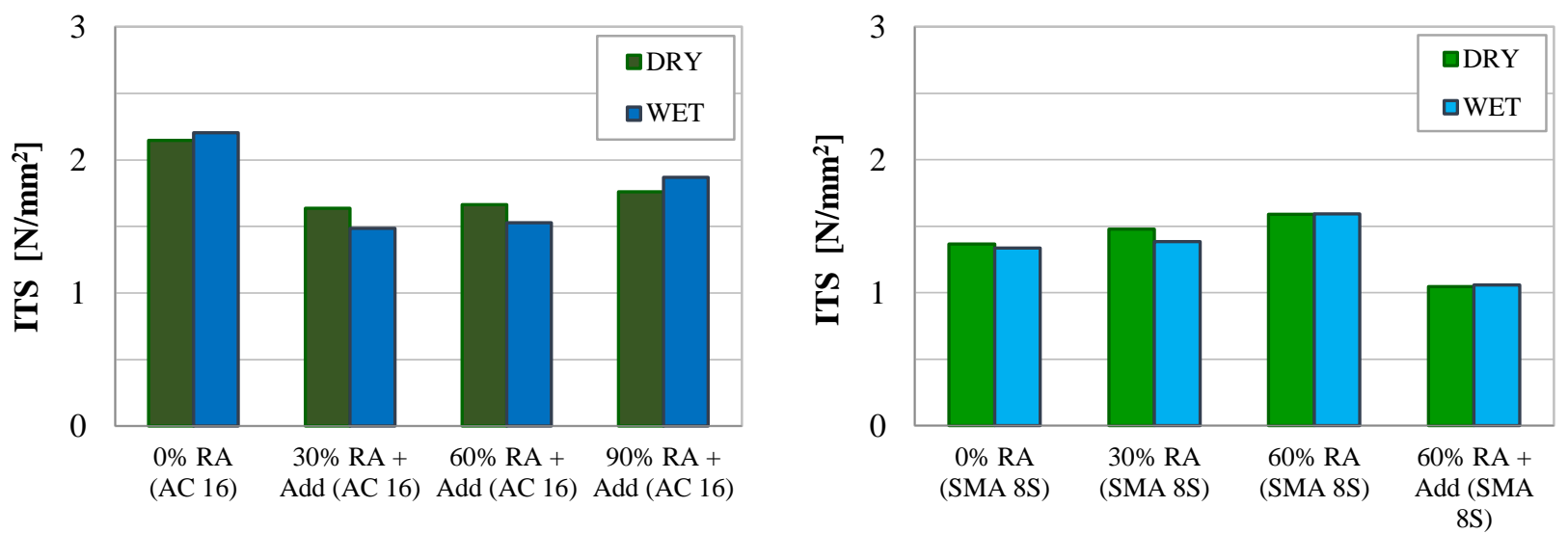

Figure 8. Indirect Tensile Strength ITS $_{\text {dry }}$ and ITS $_{\text {wet }}$ for the SMA $8 \mathrm{~S}$ and AC 16 asphalt mixes

Rutting resistance - Wheel tracking tests

The rutting resistance of the investigated asphalt mixes has been determined by conducting Uniaxial Compression Tests (UCT) and Wheel Tracking Tests (WTT). The results of the WTT, are plotted in Figure 9 and Figure 10. Both, the SMA and the AC mixtures, apart from the SMA $8 \mathrm{~S}$ with $60 \% \mathrm{RA}+$ Additive mixture, show a relatively good resistance to permanent deformation. This discrepancy is conform to the stiffness results (Figure 5).

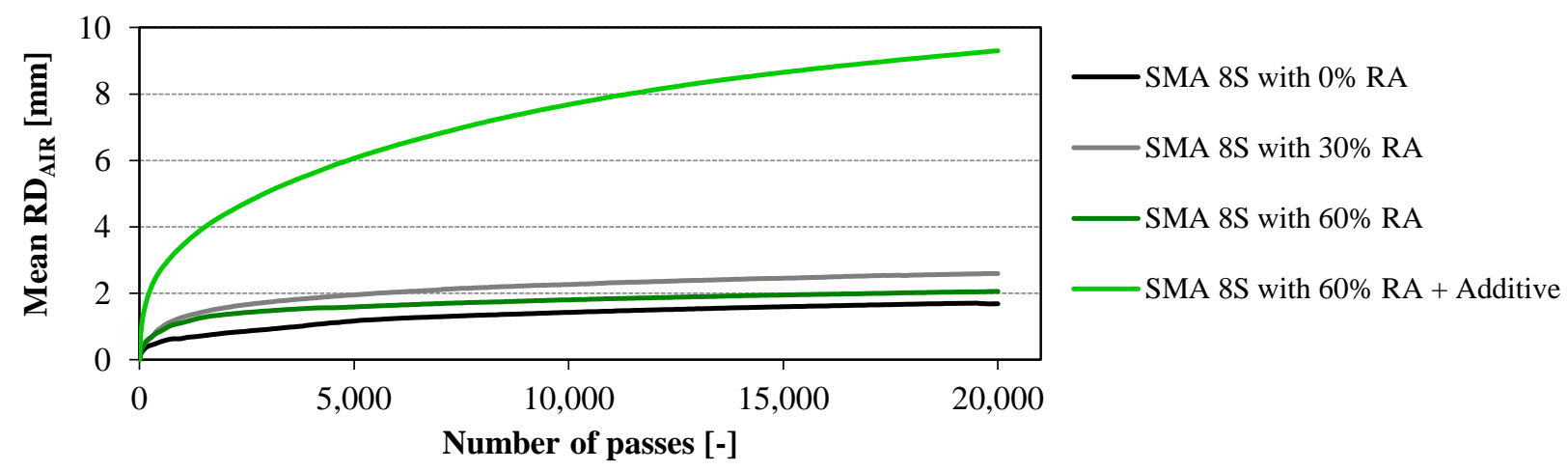

Figure 9. Wheel tracking curves for the SMA $8 \mathrm{~S}$ asphalt mixes 


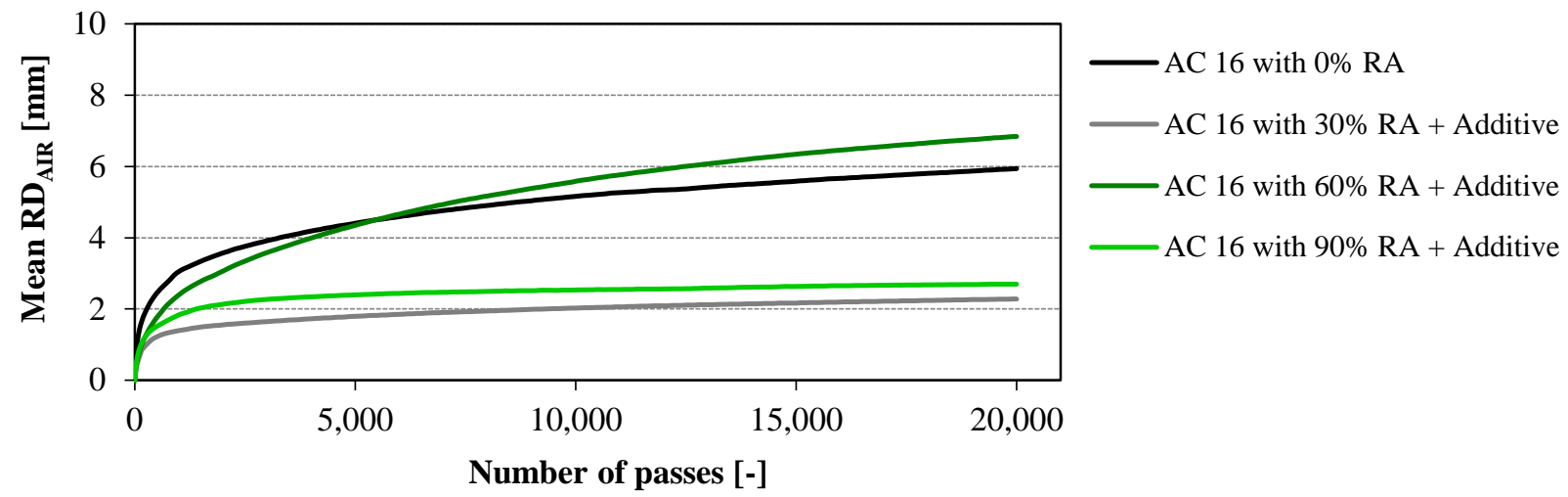

Figure 10. Wheel tracking curves for the AC 16 asphalt mixes

$\underline{\text { Rutting resistance- Uniaxial Compression tests }}$

Additional, uniaxial compression tests were carried out to describe the rutting resistance of the different wearing course asphalt mixtures. Taking into account the dependency of the permanent deformation behavior to the temperature as well as the stress level. The applied test conditions are summarised in Table 7.

Table 7. Testing conditions

\begin{tabular}{|c|c|c|c|}
\hline Temperature $\left[\mathbf{C}^{\circ}\right]$ & Frequency $[\mathbf{H z}]$ & Test mode $[-]$ & Stress level $[\mathbf{M P a}]$ \\
\hline $30,40,50$ & 10 & Force controlled & 0.1 to 0.925 \\
\hline
\end{tabular}

Figure 11 and Figure 12 show exemplary the accumulated plastic strains at the hundredth load cycle in dependency of the initial elastic strain. Regarding the SMA mixtures, the mixture with 60\% RA + Additives leads to the deepest rut death, which was also observed in the wheel tracking test as well as in the binder characterisation. The other three SMA materials behave similar as also observed from the wheel tracking tests.

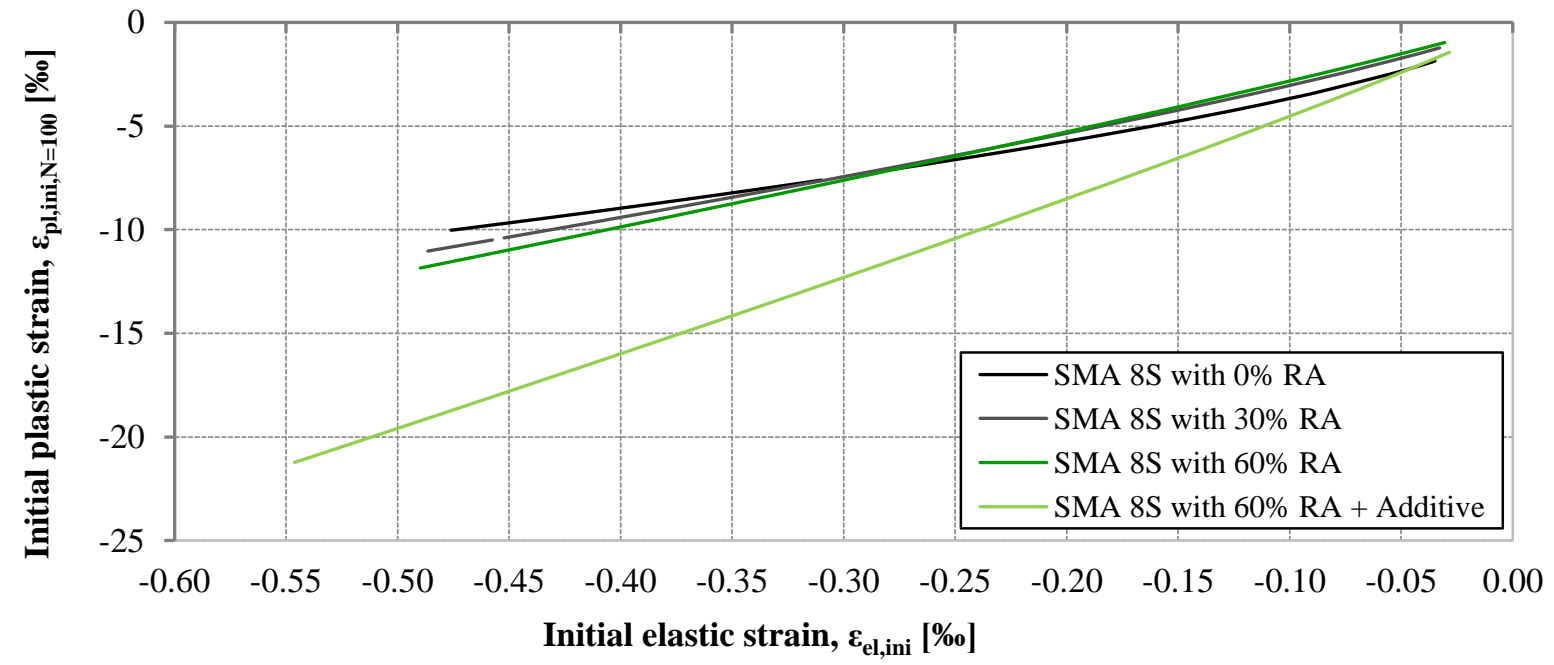

Figure 11. Results of the uniaxial compression test for the SMA $8 \mathrm{~S}$ asphalt mixes

Regarding the AC mixtures a clear relation between the plastic deformation behaviour and the amount of RA can be seen. An increasing amount of RA in combination with the use of additives leads to a lower risk of rutting. In case of the AC materials this conclusion does not apply for the wheel tracking results.

In summary, the results of the wheel tracking tests and the uniaxial compression tests do not lead to a consistent ranking of the asphalt mixtures. Regarding the SMA materials the plastic deformation results of the two different laboratory tests can be qualitatively compared, whereas the AC mixtures results show different rankings. Based on the limited number of data a final conclusion regarding the comparability of the tests cannot be drawn. Further investigations are needed to describe a possibly existing relation between the outcomes of the different procedures describing rutting resistance. 
However, the UCT's cover a wider range of material behavior due to the variation of testing conditions, while at the same time these conditions can be used as input data for pavement performance predictions. Based on these facts the uniaxial compression test has a greater potential for further investigations.

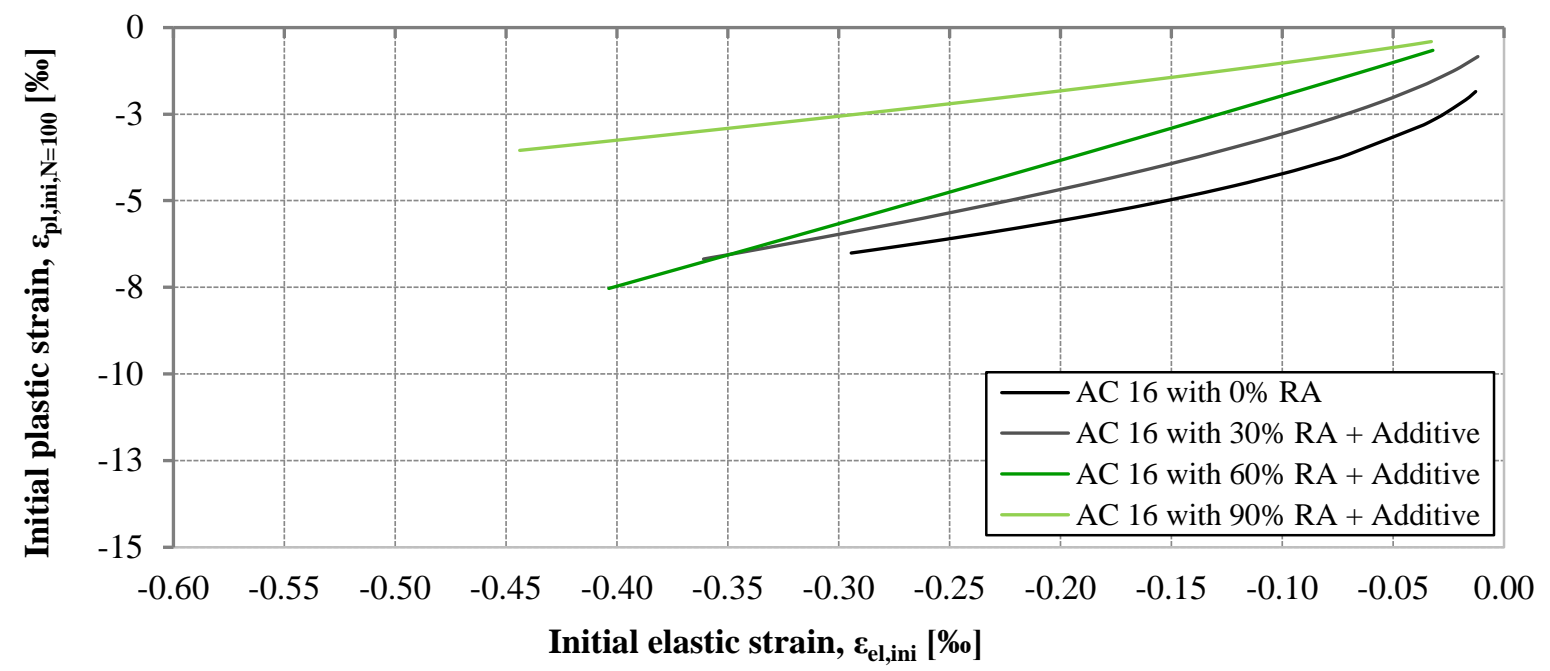

Figure 12. Results of the uniaxial compression test for the AC 16 asphalt mixes

\subsection{Conclusions}

Against the common concern that the high quality material requirements for wearing courses are not met if the major volumetric component of the mix originates from a recycled material it can be concluded that, provided that appropriate mix design procedures are carried out and fractioned and characterised reclaimed asphalt is available, the use of high recycling rates in asphalt wearing courses does not cause inevitable worse performance characteristics.

\section{ACKNOWLEDGEMENTS}

The research presented in this paper was carried out as part of the CEDR Transnational Road research Programme Call 2012. The funding for the research is provided by the national road administrations of Denmark, Finland, Germany, Ireland, Netherlands and Norway.

The authors thanks also Gustavo Canon Falla from the Technical University of Dresden, Ana Jimenez Del Barco Carrion and Gustavo Menegusso Pires from the University of Nottingham and Ciro Maurizio Di Liberto from the University of Palermo for their support.

\section{REFERENCES}

[1] Direct-MAT - Dismantling and Recycling Techniques for road Materials, 2011: Available at: http://www.directmat.eu/.

[2] Re-Road - End of Life Strategies of Asphalt Pavements, 2012: Available at: http://re-road.fehrl.org/.

[3] Unlocking the full potential of reclaimed asphalt pavements (RAP) - High quality asphalt courses incorporating more than 90\% RAP; a case study, J. C. Arnold, M. Nölting, G. Riebesehl, C. Denck, Proceedings $5^{\text {th }}$ Eurasphalt \& Eurobitume Congress, held on 13-15th June 2012, paper O5EE-187, Istanbul, Turkey.

[4] Effects on Availability of Road Network, Effects of constituent materials, recycled and secondary sources materials and construction conditions on pavements durability derived from literature and site data review, K. Mollenhauer, C. Nicholls, K. Varveri, A. Tabakovi, C. McNally, A. Gibney, EARN, Deliverable 3, 2014 : Availible at http://www.trl.co.uk/media/263523/earn_d3_effects_found_from_reviews.pdf.

[5] High-content RA warm asphalt mixture design, F. Wellner, G. Canon Falla, R. Millow, A. Blasl, G. Di Mino, C. M. Di Liberto, S. Noto, D. Lo Presti, A. J. Del Barco Carrion, G. Airey, AllBack2Pave, Deliverable D2.1, 2015: Available at http://allback2pave.fehrl.org/.

[6] TL-Asphalt StB 07:2013 - Technische Lieferbedingungen für Asphaltmischgut für den Bau von Verkehrsflächenbefestigungen. Köln: FGSV Verlag GmbH, 2013, Germany.

[7] ANAS, Capitolato speciale d'appalto - Norme Tecniche, Azienda Nazionale Autonoma delle Strade, 2010, Italy.

[8] BS EN 12697-4:2005 - BRITISH STANDARDS INSTITUTION, 2005. BS EN 12697-4:2005. Bituminous mixtures - Test methods for hot mix asphalt — Part 4: Bitumen recovery: Fractionating column, 2005.

[9] BS EN 14771:2012 - BRITISH STANDARDS INSTITUTION, 2012. BS EN 14771:2012. Bitumen and bituminous binders — Determination of flexural creep stiffness — Bending Beam Rheometer (BBR), 2012. 
[10] BS EN 14770:2012 - BRITISH STANDARDS INSTITUTION, 2012. BS EN 14770:2012. Bitumen and bituminous binders - Determination of complex shear modulus and phase angle — Dynamic Shear Rheometer (DSR), 2012.

[11] EN 12697-26:2012 - Bituminous mixtures - Test methods for hot mix asphalt - Part 26: Stiffness, 2012.

[12] EN 12697-24:2012 - Bituminous mixtures - Test methods for hot mix asphalt - Part 24: Resistance to fatigue, 2012.

[13] AL Sp-Asphalt 09 - Arbeitsanleitung zur Bestimmung des Steifigkeits- und Ermüdungsverhaltens von Asphalten mit dem Spaltzug-Schwellversuch als Eingangsgröße in die Dimensionierung Forschungsgesellschaft für Straßenund Verkehrswesen, FGSV Verlag GmbH, Köln, 2009, Germany.

[14] EN 12697-12:2008, Bituminous mixtures -Test methods for hot mix asphalt - Part 12: Determination of the water sensitivity of bituminous specimens, 2088.

[15] EN 12697-23:2003, Bituminous mixtures - Test methods for hot mix asphalt — Part 23: Determination of the indirect tensile strength of bituminous specimens, 2003. 